82

\title{
The impact of our questions on Information Technology policy and practice
}

\author{
David Benzie \\ College of St. Mark and St. John \\ Plymouth \\ United Kingdom
}

\begin{abstract}
Questioning is a fundamental characteristic of a democratic society. However, we often forget that questions do not arise out of a vacuum. Rather, these reflect the epistemological standpoint of the one who asks them, in a profound way.

This paper argues that many of the questions which are currently being asked about the role of IT in education, reflect a particular view of the purpose and nature of education in a technology based society. Examples of typical questions are presented and it is then argued that these are based on a flawed premise. The reason why such questions get asked, is discussed.

Finally an alternative set of questions is presented and it is argued that if questions like these are asked, then the role of IT in education will develop in ways which are more sympathetic to the needs of learners.
\end{abstract}

Main conference themes: national policies, evaluation

Educational areas:

Study topics:

Secondary keywords: learning models 


\section{INTRODUCTION}

We live in an age where questions are a heavily traded commodity. The concept of questioning is readily accepted as being at the heart of a modern democracy. Yet there is relatively little discussion about the interaction between the questions which get asked, and the path which we then follow simply because a question is phrased in a particular way. The interaction between question style and course of action is particularly important when an innovation such as Information Technology (IT) in education is being evaluated. The course of the innovation may well be critically influenced by the question style. Just think what might have happened if the American railroad pioneers had had the question: "How can we work with the indigenous peoples so that we all benefit from this machine?" at the forefront of their minds!

The aim of this paper is to contribute to the debate about IT research questions which Marshall [1] raised at the IFIP conference in Gmunden. Marshall argued that epistemological perspective has a critical bearing on the questions which are asked, and on the sort of answers which are looked for. This paper argues that some questions - and this applies to many of the questions which noneducationalists are asking about the role of IT in school are either irrelevant or seriously misleading.

For a number of years, there has been a recognition in the research community that the outcomes of research are critically influenced by methodological style. Ridgway [2], for example, discusses the need for research on IT in education and in this context contrasts laboratory studies with studies based on classes taught by enthusiasts and with studies of representative classes. The former may lead to apparently clear and unambiguous statements such as "students following the computer based programme of activities did significantly better $(p=0.01)$ than those who did the paper based activities..." but they are hardly generalizable. Such precision is rarely achievable (and even harder to justify) when reporting studies on representative classrooms. The Bennett research, discussed in McIntyre [3], on teaching style and pupil achievement provides a classic example of how the desire to categorise classroom complexity in an apparently straightforward way can generate a good deal of heat but rather less light. The scientific tradition (particularly as portrayed to pupils in school science) is usually associated with questions which yield apparently comprehensive and unambiguous answers. Given the desire of most politicians to find simple answers to complex questions and given their introduction to the nature of an investigative question in the school science classroom, it is hardly surprising that they come up with questions about the role of technology in education which appear to come out of a junior science text book. Indeed, one might even paraphrase the Jesuits' 
statement: "Give me a child until he is 7 and I will show you the man," as "Give me a child until he understands the notion of a question, and I will show you the questions which he will ask."

\section{Are there questions which we should not ask?}

It may seem heretical to suggest that some questions should not be asked, but just remember the old music hall comedians who solicited a straight-forward answer to the enquiry, "Have you stopped beating your wife?" For those with anything other than the sharpest of wits, a rapid response was most unwise! This didn't stop the innocent from falling in a well-set trap, though fortunately the only consequence was a red face and plenty of laughs. The question has parallels in education, but the consequence of falling for the trap is altogether more serious.

The hidden false premise lies at the heart of many questions we should be particularly wary of. A topical example might run along these lines, "Do children taught by a computerised interactive learning system make better progress at arithmetic than those who use traditional paper and pencil?" Amongst other things, this question is based on the attractive, but erroneous, assumption that what is worth learning is fixed, and that the problems in education principally revolve around the search for better ways of teaching a largely static corpus of knowledge. But one of the fundamental points about the computer is that it renders the assumption void; it is pointless to carry on trying to teach the same things which we have always taught, using optimized versions of traditional techniques. Computers revalue skills - some up and some down - and so we need to re-assess what it is we wish to teach. Why memorize large numbers of facts when good information skills can locate detail in a computerized database? Much better to focus on the ability to synthesize. Why spend ages learning to draw neat graphs when your spreadsheet can do it better in seconds? What you really need now is the ability to select an appropriate graphical representation for your data. Why simply read about peoples lives in other countries when it is possible to communicate directly and engage in collaborative projects, thus building personal relationships? The ability to organize and to work as a team member is increasingly important. In addition, the question is covertly inferred from increasingly suspect learning theory - a point which is discussed at length by Marshall.

Kemmis [4], quoted in Beynon \& Mackay [5], argues effectively that research on IT in education should not be designed to serve decisionmakers outside of the setting, as opposed to those within it. Yet this contrasts strongly with the fundamental questions which the MacFarlane report [6] identifies such as "How can high quality environments for the support of learning be created and maintained which will be able to handle the expected growth in (student) 
numbers?" and "How can an increasing effectiveness and the containment of costs be reconciled with a high quality of learning experience?" This report is predominantly a response to a political, rather than an educational agenda and it is currently exerting a strong influence on IT development programmes in UK higher education. So the questions which are driving research, have largely been shaped by those outside of education who have an agenda dominated by concepts of economic efficiency, rather than by desire to re-assess the nature of teaching and learning in the light of an innovation which is every bit as significant as the printing press. This is precisely the situation which Kemmis warned against.

So what do some of these misleading or irrelevant questions look like? Here are a few - if you look around you will find plenty more!

1. "Do pupils who have access to a computer, achieve more?"

The first problem with this type of question lies with the definition of achievement. Is it defined merely in terms of the ability to complete atomized tasks? What about evaluating process achievement? The second problem relates to the definition of access. Does an average of 10 minutes per day working on trivial, repetitive or routine tasks count as "having access"? If not, what about 20 minutes? Efforts to produce a sophisticated measure of "computer access" are more likely to distract than illuminate.

2. "Do pupils who spend 15 minutes a day using an Intelligent Learning System improve their ability at arithmetic?"

This is inferred from a traditional definition of what is worth learning; the question is likely to be studied in a context which relies on increasingly discredited models of the learning process. The question also suggests notions of "learning efficiency" which are essentially utilitarian and which are devoid of social consideration.

3. "What gains in efficiency do we get from using IT in education?"

Another echo of the unchanging curriculum and an almost certain indication of a failure to recognize that you need IT to acquire IT skills! Furthermore, the question confounds efficiency with effectiveness. Something may be efficient, i.e., done quickly and with little cost relative to other attempts, but still be ineffective or outmoded.

4. "Are computers cost-effective?"

Who defines the objectives which enable an assessment to be made of costeffectiveness? Yet another incarnation of the unchanging curriculum assumption. 
The truth is not so much that there are questions we should not ask, but that we should ask our questions knowingly; we should recognize that the way we phrase our questions will, to a large degree, dictate the path we subsequently tread. With IT, there is a huge danger that control of the questions will be taken by those whose first loyalty is not to teaching and learning.

\section{An alternative set of questions}

Despite the pitfalls, there are plenty of questions well worth asking about the role of IT in education. Indeed, there are many who are trying to ask questions along the following lines:

1. "How does IT change the nature of what is worth learning?"

What, for example, does 'doing maths' mean when you have a readily available tool for calculating, drawing graphs, and doing algebra and calculus?

2. "What is the difference in the nature of the learning activities of pupils using, as contrasted with pupils not using, IT?"

3. "Is there still a case for a word-driven curriculum?"

Traditionally we have asked pupils to demonstrate their mastery of a subject through the use of words - usually written but sometimes spoken. IT is beginning to open up the possibility of a visual curriculum where pupils can use images and sounds to demonstrate understanding.

4. "What are the mental models (if any) we should give to learners to help them come to terms with large information spaces?"

The concept of a book library is easy to demonstrate to a young child, but how do we model the Internet for pupils who cannot handle abstraction?

5. "Can we use computers to support desirable, but elusive, classroom activities?"

There is research which claims to show that computers can be effectively used to support activities such as group work and problem solving. Can we go further and use IT to support pupils with a range of preferred learning styles?

Question 2 was posed in the comprehensive ImpactT study [7] which was carried out in UK schools. The results of the study provide plenty of thoughtful material for the reflective practitioner (and the responsible administrator) but, unsurprisingly, it is a poor source of sound-bites. A consequence of this is that the report has had a somewhat lower profile than one might have reasonably expected. Once again, the tougher, but ultimately more worthwhile, questions are sidelined. 


\section{CONCLUDING REMARKS}

We must not lose sight of the significance of our questions to the path we will follow. There is a huge weight of institutional inertia, alternative agendas, lack of vision and plain misunderstanding which will impose on our questions in ways we may not wish, unless we are prepared to challenge the hidden false premise. One such ever present, but rarely articulated, premise is that IT is nothing more than a technology to teach what we have always taught, in a more efficient way.

\section{REFERENCES}

1. Marshall, G. (1993) Informatics and changes in learning: the American dilemma and opposing epistemological perspectives and unanswered questions, in Informatics and Changes in Learning, (eds. Johnson, D.C. and Samways, B.), Elsevier Science Publishers, Amsterdam.

2. Ridgway, J. (1986) Research Needs for Educational Uses of Information Technology. InTER Occasional Paper ITE/9/86 Edition 1. Department of Psychology, Lancaster University.

3. McIntyre, D. (1986) Teaching styles and pupil progress: a review of Bennett's study, in Case Studies in Classroom Research, (ed. Hammersley, M.). Open University, Milton Keynes.

4. Kemmis, S. (1988) Educational computing: how do we know what we are getting? Paper to the Educational Computing Conference, Melbourne, July.

5. Beynon. J. and Mackay. H. (1993) Computers into Classrooms: More Questions than Answers. Falmer Press, London.

6. MacFarlane Report. (1992). Teaching and Learning in An Expanding Higher Education System. CSUP, Scotland.

7. Watson, D.M. (ed.) (1993) The ImpacT Report: An Evaluation of the Impact of Information Technology on Children's Achievements in Primary and Secondary Schools. King's College, London. 